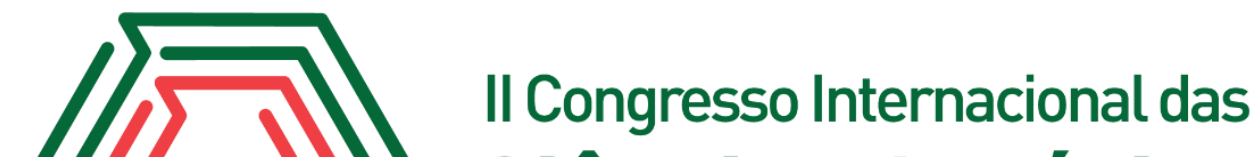 Ciências Agrárias COINTER - PDVAgro 2017
}

\section{CONSUMO DE ALIMENTOS: CONVENCIONAIS X HIDROPÔNICOS X ORGÂNICOS}

\author{
Apresentação: Pôster
}

Carmem Sara Pinheiro de Oliveira ${ }^{1}$; Allison Ferreira de Lima ${ }^{2}$

\section{Introdução}

A cada dia que passa o consumidor se torna mais exigente. Com isso vem o aumento da preocupação da origem do alimento ingerido, assim como seus possíveis aspectos toxicológicos e suas características físicas.

A responsabilidade ecológica e o desejo por uma agricultura de menor impacto ao meio ambiente, têm sido responsáveis por um melhor desempenho na tecnologia agrícola, os quais encontram subsídios quando considerada a concepção de que muitos consumidores desejam produtos saudáveis, bonitos e disponíveis ao consumo, durante o ano todo.

É necessário também levar em consideração que o alimento do futuro produzido localmente deverá ser um dos fatores mais importantes para garantir a sustentabilidade na provisão de alimentos, no qual produtores e consumidores parecem considerar essas questões de grande interesse.

Portanto, justifica-se a importância deste estudo em virtude do consumo de alimentos terem aumentado significativamente nos últimos anos, pelo crescente aumento da população, bem como pela tendência de mudanças nos hábitos alimentares dos consumidores, tornando-se inevitável o melhoramento da produção, assim como o entendimentos acerca das necessidades dos usuários.

Visando a crescente expansão da agricultura em todo país nos últimos anos, este trabalho teve por principal objetivo avaliar comparativamente a preferência de consumidores frente aos sistemas de cultivo Convencional, Hidropônico e Orgânico.

\footnotetext{
${ }^{1}$ Mestra em Aquicultura, Universidade Federal de Santa Catarina, sarinhac.s@hotmail.com

${ }^{2}$ Mestrando em Ciência Animal, Universidade Federal Rural do Semi-Árido, henresito@hotmail.com
} 


\section{Fundamentação Teórica}

A preocupação com o que se está sendo consumido, estende-se principalmente devido a qualidade nutricional, microbiológica e sensorial dos alimentos, alterada em função do sistema de cultivo (convencional, hidropônico, orgânico, etc.) (CALDAS, 1999).

No sistema de cultivo convencional é permitido o uso de agrotóxicos e fertilizantes químicos altamente solúveis. Para Darolt (2003), o modelo convencional de agricultura já se mostrou intolerável para o meio ambiente, para os agricultores e consumidores, devido ao grande número problemas gerados, tais como, erosão, baixa produtividade das terras e culturas, doenças, etc., o que chamou a atenção da opinião pública acerca de sua alimentação.

Já no sistema de cultivo hidropônico as plantas são desenvolvidas na ausência do solo, no qual os nutrientes que as plantas necessitam para seu crescimento são fornecidos somente pela água. Por isso esse sistema de cultivo pode ser desenvolvido nas regiões mais distintas. A hidroponia originou-se através de experimentos que buscavam determinar os elementos essenciais e suas considerações ao desenvolvimento vegetal, quando extraídos do solo, do ar e da água (MORAES, 1997).

Com relação a produção orgânica, o agricultor não pode utilizar agrotóxico e fertilizante químico (BRASIL, 1999). Assim sendo, para que uma atividade seja considerada como orgânica deve apresentar: produtos saudáveis e de elevado valor nutricional, isentos de contaminantes que ponham em risco a saúde do consumidor, do agricultor e do meio ambiente; a preservação e a ampliação da biodiversidade dos ecossistemas; a conservação das condições físicas, químicas e biológicas do solo, da água e do ar; a integração entre os diferentes segmentos da cadeia produtiva e de consumo e a regionalização da produção e comércio (BRASIL, 2003).

\section{Metodologia}

O método utilizado neste estudo foi a pesquisa descritiva conclusiva, onde a mesma teve o objetivo de quantificar os dados e gerar resultados perante a amostra em questão. Os dados foram gerados a partir de entrevistas estruturadas que ocorreram em dezembro de 2016 no município de Natal - RN, totalizando 50 sujeitos amostrais. As questões abordaram qual o tipo de cultivo consumido e qual o preterido, bem como os fatores que os levam a tais escolhas. Posteriormente, os 
dados foram tabulados no Excel e expressos estatisticamente em percentual.

\section{Resultados e Discussões}

Primeiramente os entrevistados foram questionados acerca de qual tipo de cultura utilizam em sua alimentação. Foi observado que 74,00\% consomem alimentos convencionais (AC), 4,00\% alimentos hidropônicos (AH) e 22,00\% alimentos orgânicos (AO). Adicionalmente foi perguntado o motivo que os levam a comprar tais alimentos e o resultado pode ser observado na Figura 1.

Figura 1: Tipos de alimentos consumidos e fatores que levam ao seu consumo. Fonte: Própria.

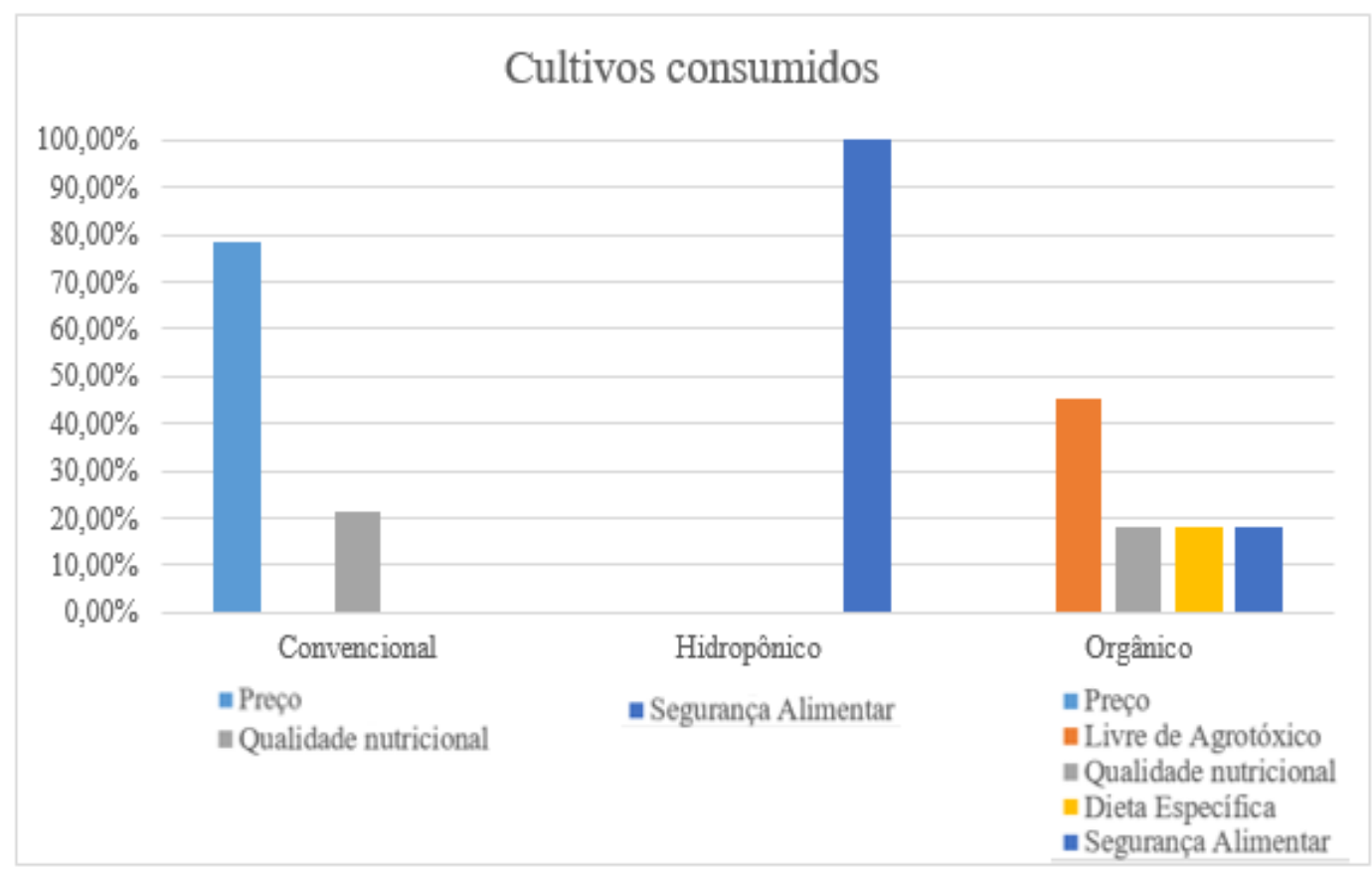

Dentre os que consomem AC, 78,37\% apresentaram o preço como sendo o principal fator que os induz na hora da compra. Campanhola e Valarini (2001), afirmam em sua pesquisa que produtos convencionais são ainda cerca de $40 \%$ mais baratos que os demais, levando a população ainda a ter um maior interesse.

Já no que diz respeito aos $\mathrm{AH}$, a segurança alimentar aparece com 100\%, indicando uma confiabilidade por quem os consome. Carmo Jr. (2002), destaca a seguridade deste cultivo que é realizado longe do solo, sem contaminantes, como bactérias, fungos, insetos e parasitas, ou seja, são mais saudáveis, pois cresceram em um ambiente altamente controlado.

No que concerne os $\mathrm{AO}$, foram apresentados mais pontos positivos, entretanto o mais destaque se dá para o fato de serem livres de agrotóxicos (45,46\%). Segundo Kathounian (2001), 
um produto orgânico além de ser livre de agrotóxicos e sem aditivos químicos, ele vai além em seus benefícios, uma vez que resulta de um sistema de produção agrícola que busca o equilíbrio ideal do manejo do solo e dos demais recursos naturais (água, plantas, animais, insetos), conservando-os a longo prazo e mantendo a harmonia desses elementos entre si e os seres humanos.

Por segundo, os mesmos entrevistados foram indagados sobre qual tipo de cultura gostariam de utilizar em sua alimentação e quais os motivos. Foi encontrado que apenas 10,00\% utilizariam os AC, $26,00 \%$ os $\mathrm{AH}$ e 64,00\% os AO. Os motivos das escolhas podem ser identificados na Figura 2.

Figura 2: Tipos de alimentos preteridos ao consumo e fatores que levariam ao mesmo. Fonte: Própria.

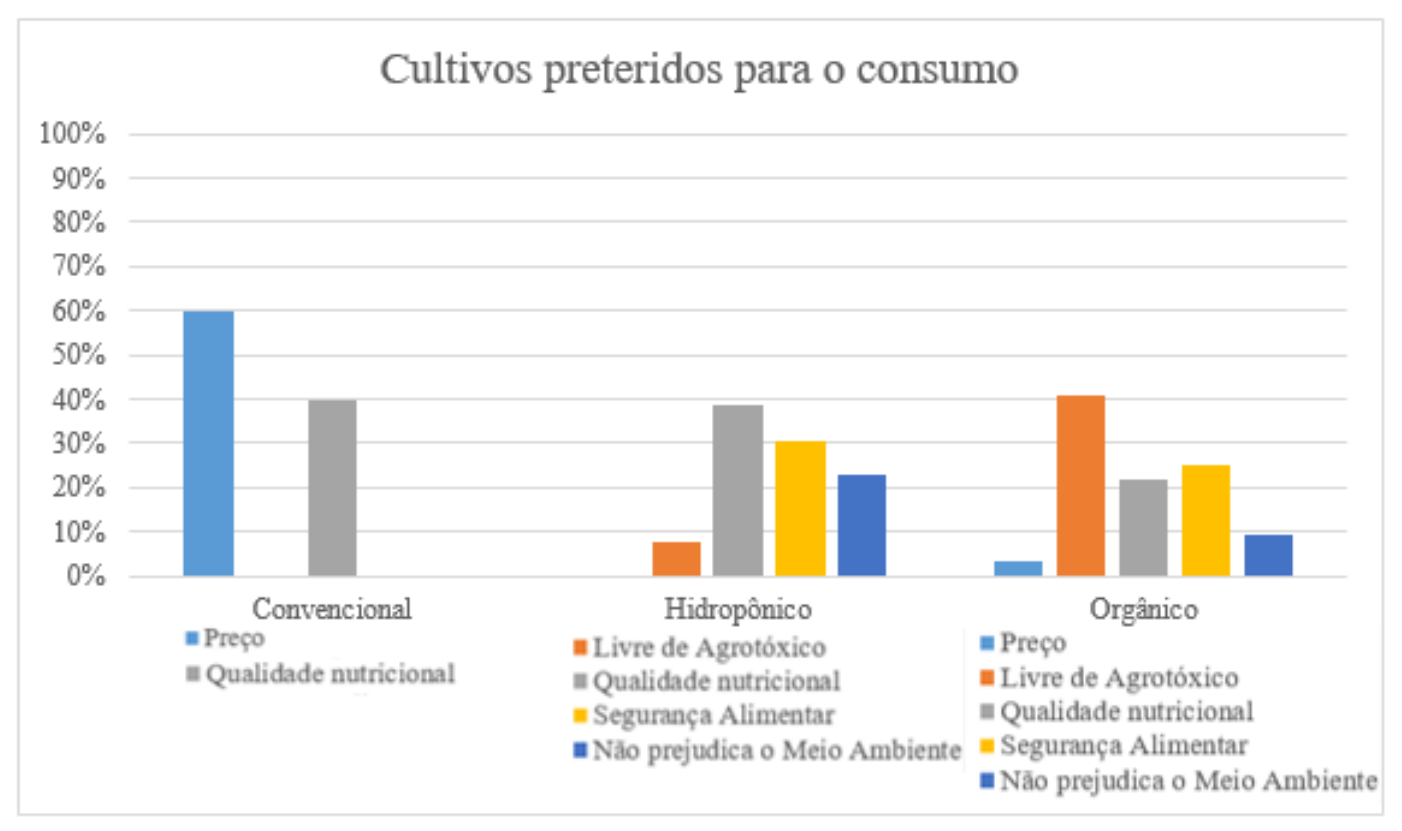

Dentre os que mantiveram o seu consumo em AC, é possível perceber que o preço $(60,00 \%)$ é o principal fator determinante para essa escolha. Já os que preferem os AH disseram a qualidade nutricional $(38,46 \%)$, uma vez que os sais neste tipo de cultivo são intensamente balanceados, seria o principal fator pela sua aquisição. O principal motivo que os conduz uma parcela dos entrevistados a consumirem AO seria o fator livre de agrotóxicos $(40,64 \%)$.

Diante do exposto, fica claro a percepção dos entrevistados que o maior benefício do alimento obtido pelo sistema de cultivo orgânico está direcionado à saúde, além de apresentar um menor impacto ambiental (DAROLT, 2003). A agricultura convencional visivelmente produz um alimento mais barato (BOURN e PRESCOTT, 2002), porém as suas implicações no quesito saúde e cuidado com o meio ambiente vêm despertando uma maior atenção da população. Em relação ao sistema de cultivo hidropônico, o mesmo apresenta custos iniciais elevados (PENNINGSFELD e KURZMANN, 1983), portanto ainda é pouco difundido no Nordeste do Brasil, porém mostra-se um 
alimento extremamente nutritivo

\section{Conclusões}

Conclui-se com o trabalho que o tipo cultivo mais consumido é o convencional e o seu principal fator se dá pelo baixo preço, o que em tempos de crise financeira se torna o parâmetro mais propício a ocorrer. Entretanto, o tipo de cultivo mais preteridos pelos entrevistados é o orgânico, por serem livres de agrotóxicos e possuírem menos danos à saúde e ao meio ambiente. $\mathrm{O}$ pouco conhecimento do sistema hidropônico no Nordeste, o torna menos visado em termos de consumo.

\section{Referências}

BOURN, D.; PRESCOTT, J. A comparison of the nutritional value, sensory qualities, and food safety of organically and a conventionally produced foods. Critical Reviews in Food Science and Nutrition, Dunedin, New Zealand, v. 42, n. 1, p. 1-34, 2002.

BRASIL. Ministério da Agricultura e do Abastecimento. IN nº 007/MAPA de 17 de maio de 1999. Normas disciplinadoras para a produção, tipificação, processamento, envase, distribuição, identificação e certificação da qualidade de produtos orgânicos, sejam de origem animal ou vegetal. Diário Oficial da União da República Federativa do Brasil, Brasília, Seção I de 19/05/99, p. 1114.

BRASIL. Ministério da Agricultura e Abastecimento. Lei no 10.831, de 23 de dezembro de 2003. Dispõe sobre a agricultura orgânica. Disponível em: 〈www.agricultura.gov.br〉. Acesso em: 28 fev. 2017.

CALDAS, E.D. Resíduos de Pesticidas em Alimentos e o Codex Alimentarius. Campinas. Bol. SBCTA, 33, 50-56, 1999.

CAmpanhola, C.; VAlarini, P. J. A Agricultura Orgânica e Seu Potencial Para o Pequeno Agricultor. Cadernos de Ciência \& Tecnologia, Brasília, v.18, n.3, p.69-101, set./dez. 2001. Disponível em: <http://atlas.sct.embrapa.br/pdf/cct/n18/cc18n303.pdf〉. Acesso em: 14 jun. 2017.

CARMO JR., R. R. O que é a hidroponia? Disponível em: <http://www.hidroponica.cjb.net>. Acesso em: 12 dez. 2016.

DAROLT, M.R. Agricultura Orgânica: Inventando o Futuro. PRONAF/MDA. Curitiba, 2000. 249 p. Atualização do livro, 2003. 
MORAES, C. A. G. Como Cultivar Tomates em sistema NFT: técnica do fluxo laminar de nutrientes. 1a. ed. DESQ Editora, Jundiaí, 148 p.,1997.

PENNINGSFELD F.; KURZMANN, P. Cultivos Hidropónicos y en Turba. $2^{a}$ ed., Ediciones Mundi-Prensa, Madrid, 1983. p. 7-64. 